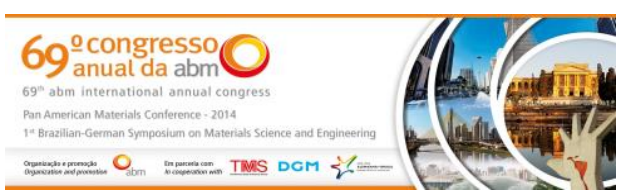

Tema: Gestão de meio ambiente e recuperação e tratamento de rejeitos

\title{
PÓ DE ACIARIA ELÉTRICA - UMA ANÁLISE DA INFLUÊNCIA DA COMPOSIÇÃO NAS ROTAS DE RECICLAGEM*
}

\author{
Pedro Jorge Walburga Keglevich de Buzin ${ }^{1}$ \\ Nestor Cezar Heck² \\ Antonio Cezar Faria Vilela ${ }^{3}$
}

\begin{abstract}
Resumo
A produção siderúrgica em usinas semi-integradas gera resíduos de processo, dentre os quais pó de aciaria elétrica (PAE). A presença de zinco e os custos crescentes para a disposição deste resíduo são fatores de motivação para sua reciclagem ou incorporação em outros materiais. Entretanto, fatores como o teor de zinco e as espécies minerais existentes, têm influência no processamento do PAE. Adicionalmente, a presença de outros elementos como o chumbo, cromo e o cloro muitas vezes afetam de modo determinante os processos de reciclagem ou aproveitamento. Neste estudo, após análise, são feitas considerações acerca da influência da composição do PAE em processos piro e hidrometalúrgicos de reciclagem. Complementando o trabalho, são feitas simulações sobre o possível comportamento de algumas espécies químicas do PAE em processos de reciclagem, com auxílio da ferramenta termodinâmica computacional FactSage.
\end{abstract}

Palavras-chave: PAE; Reciclagem; Termodinâmica computacional.

\section{ELECTRIC ARC FURNACE DUST - ANALYSIS OF THE INFLUENCE OF COMPOSITION ON THE RECYCLING ROUTES}

\section{Abstract}

The steel production in mini mills generates several process residues, among them the electric arc furnace dust (EAFD). The presence of zinc in EAFD and the rising costs for disposal of this waste are motivating factors for its recycling or incorporation into other materials. However, factors such as the zinc content and the mineral species influence the processing of the PAE. Additionally, the presence of other elements such as lead, chromium and chlorine often affect in a decisive way the processes of recycling or recovery. In this study, considerations are made about the influence of the composition of EAFD on pyro and hydrometallurgical processes. Complementing this work, thermodynamic considerations are made with the aid of the tool FactSage about the possible behavior of some chemical species of EAFD in the recycling processes.

Keywords: EAFD; Recycling; Computational thermodynamics.

1 M.Sc, Eng Quim., aluno do Programa de Pós-Graduação em Eng. de Minas, Metalúrgica e de Materiais, PPGE3M; LEAmet; UFRGS, Porto Alegre, RS, Brasil; pedrobuzin@terra.com.br.

2 Dr.-Ing., Professor, PPGE3M, Núcleo de Termodinâmica Computacional para a Metalurgia, NTCm; Depto. de Metalurgia, UFRGS, Porto Alegre, RS, Brasil; heck@ufrgs.br.

3 Dr.-Ing., Professor, PPGE3M, Laboratório de siderurgia, LASID, UFRGS, Porto Alegre, Brasil; vilela@ufrgs.br.

* Contribuição técnica ao 69ํ Congresso Anual da ABM - Internacional e ao 14ํㅡㄹ ENEMET - Encontro Nacional de Estudantes de Engenharia Metalúrgica, de Materiais e de Minas, 21 a 25 de julho de 2014, São Paulo, SP, Brasil. 


\section{INTRODUÇÃO}

A tecnologia de fabricação de aço utilizada pela maior parte das usinas semiintegradas ou mini-mills é a aciaria elétrica, a qual emprega como equipamento de fusão da carga o forno elétrico a arco - FEA. Durante a operação do FEA, ocorre a geração do pó de aciaria elétrica - PAE. Este resíduo é originado pela vaporização de metais ferrosos, não ferrosos e ejeção e arraste de partículas do banho metálico, escória e outros [1]. O PAE, na forma de fino particulado, é carreado do forno juntamente com gases provenientes da fusão e refino da carga, além de ar admitido para a etapa de pós-combustão e refrigeração. É usualmente retido em sistemas de despoeiramento a seco e a quantidade gerada representa entre 1 e $2 \%$ da produção de aço da usina.

A composição do PAE depende da sucata e demais insumos do processo. Interferem também os mecanismos de sua formação e parâmetros específicos de cada usina. Assim, o PAE é o resultado final de uma série de fenômenos que ocorrem desde a sua formação inicial no interior do forno até os sucessivos equilíbrios físico-químicos pelos quais passa durante sua trajetória até a captação no sistema de despoeiramento e que definem sua composição química e mineral. De maneira geral, os principais constituintes do PAE são óxidos sólidos de ferro e zinco: Zincita $(\mathrm{ZnO})$ e Franklinita $\left(\mathrm{ZnFe}_{2} \mathrm{O}_{4}\right)$. O ferro é usualmente encontrado no PAE, além do contido na Franklinita, principalmente como Magnetita $\left(\mathrm{Fe}_{3} \mathrm{O}_{4}\right)$ [2]. Vários outros elementos podem estar presentes em concentrações variadas.

Segundo Nyirenda [2], a composição das poeiras é extremamente variável, podendo sofrer alterações não somente de um dia para o outro, mas de corrida para corrida de uma mesma usina. Pickles [3] cita a presença do cálcio como o terceiro metal em maior quantidade no PAE e numerosos outros elementos são encontrados em baixas concentrações, como chumbo, silício, alumínio, manganês, magnésio cromo, níquel, cobre e cádmio. A maioria dos elementos aparece combinada com o oxigênio e o cloro encontra-se na maior parte como cloretos. Existem também fluoretos, sulfatos e sulfetos. A presença de metais pesados como chumbo e cádmio confere periculosidade a este resíduo. Está listado no anexo B da NBR 10004 [4], sendo, portanto, classificado como resíduo classe I, perigoso.

Em anos recentes tem-se observado um crescimento no teor de cloro do PAE, motivado pelo aumento na utilização de sucatas contendo impurezas com este elemento. Por este motivo, muitas vezes o cloro é o elemento mais abundante após ferro, zinco e oxigênio. Teores em torno de $5 \%$ em massa de cloro no PAE como composição média têm sido relatados [5].

Em razão de sua periculosidade, os custos de destinação ambiental do PAE tem se elevado nos últimos anos, tanto em razão das maiores exigências e controle dos locais de destinação (ARIPs), como em função da logística. Em paralelo, atualmente existe o esforço para a melhoria de indicadores de sustentabilidade dos processos siderúrgicos. Estes fatores têm incentivado o desenvolvimento e implementação de novas soluções para este resíduo, tais como a reciclagem, retorno ao processo produtivo de aço ou mesmo incorporação em outros materiais.

Entretanto, além da questão econômica, aspectos relacionados às propriedades físicas e composição química e mineral do PAE têm colocado obstáculos a serem superados para viabilização técnica e comercial das propostas de destinação. Este trabalho, portanto, tem como objetivo analisar questões relacionadas à influência exercida pela composição química e mineral do PAE em processos de reciclagem deste resíduo.

\footnotetext{
* Contribuição técnica ao $69^{\circ}$ Congresso Anual da ABM - Internacional e ao 14ํㅡㄹ ENEMET - Encontro Nacional de Estudantes de Engenharia Metalúrgica, de Materiais e de Minas, 21 a 25 de julho de 2014, São Paulo, SP, Brasil.
} 


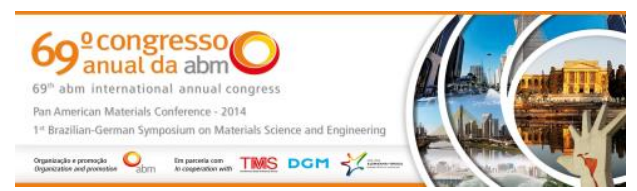

\section{METODOLOGIA}

Neste trabalho é feita uma integração de informações disponíveis na literatura juntamente com outras, originadas de discussões em eventos e congressos, acerca de propriedades e do comportamento das poeiras de aciaria em processos piro e hidrometalúrgicos de reciclagem.

A partir desta análise, são comentadas as possíveis influências que aspectos relacionados à composição e à mineralogia do PAE podem trazer ao processamento deste resíduo.

Para alguns casos particulares, equilíbrios termodinâmicos referentes à formação e vaporização de cloretos em processos pirometalúrgicos, e de dissolução de minerais em processos hidrometalúrgicos, foram determinados com base num sistema de composição química simplificada, e são discutidos ao final do trabalho.

A etapa referente à recuperação eletrolítica de zinco de soluções de sulfato, comum em vários processos também é comentada.

Os equilíbrios foram determinados utilizando o módulo Equilib do software FactSage (versão 6.4), o qual é descrito detalhadamente por Bale et al. [6].

As seguintes bases de dados foram empregadas nestas determinações:

- FToxid - FACT oxide compounds and solutions database [2013];

- FactPS - FactSage pure substances database [2013].

\section{A RECICLAGEM DO PAE}

\subsection{Avaliação Preliminar dos Processos de Reciclagem}

A pesquisa e desenvolvimento de processos de reciclagem das poeiras de aciaria já vêm de longa data e inúmeros processos tanto hidro como pirometalúrgicos ou mesmo mistos têm sido apresentados à comunidade aciarista. Outras soluções, como a incorporação do PAE em outros materiais, tanto em temperatura ambiente como em altas temperaturas, também têm sido propostas. Entretanto, somente os processos pirometalúrgicos - HTMR - (High Temperature Metals Recovery) têm alcançado maior implementação comercial, sendo a maioria deles variações do processo Waelz [3].

Um dos atrativos para a reciclagem das poeiras de aciaria é que este resíduo contém em geral teores entre 50 e $60 \%$ de ferro e zinco somados [7]. Entretanto, na maioria dos processos, somente a recuperação do zinco é realizada. Assim, o valor associado à recuperação deste metal, contribui de maneira importante para a viabilidade econômica da atividade. Sob um ponto de vista de avaliação prévia, alguns requisitos mínimos devem ser atendidos pelos processos para que possa existir uma expectativa favorável de suas possibilidades de implementação:

a) Capacidade de suportar a variação de composição das poeiras processadas, dentro de uma faixa de aceitação pré-determinada, incluindo-se o teor de zinco.

b) Possuir as correntes de massa e energia perfeitamente delimitadas, de modo a possibilitar a avaliação econômica e os investimentos necessários ao atendimento dos aspectos ambientais da proposta.

c) Oferecer competitividade econômica e/ou de sustentabilidade em relação a outras alternativas oferecidas pelo mercado.

Dentro deste contexto, Southwick [8] informa que nos EUA nos últimos 22 anos a maioria dos novos processos de recuperação de poeiras de aciaria não tiveram êxito, restando em operação as tecnologias mais antigas, como o processo Waelz.

\footnotetext{
* Contribuição técnica ao $69^{\circ}$ Congresso Anual da ABM - Internacional e ao 14ํㅡㄹ ENEMET - Encontro Nacional de Estudantes de Engenharia Metalúrgica, de Materiais e de Minas, 21 a 25 de julho de 2014, São Paulo, SP, Brasil.
} 


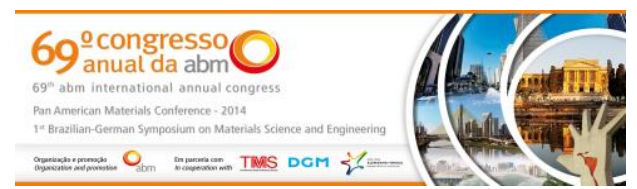

Em processos com a tecnologia Waelz, geralmente há a combustão conjunta de carbono ou outro combustível para prover a energia necessária às reações de redução. Desta maneira, o conteúdo de zinco dos gases é diluído e normalmente existe uma alta concentração de $\mathrm{CO}_{2}$ e mesmo $\mathrm{H}_{2} \mathrm{O}$ na corrente gasosa que transita pelo equipamento. Por ocasião do resfriamento dos gases, novos equilíbrios termodinâmicos têm lugar, ocorrendo a reoxidação do zinco [9].

Nos processos pirometalúrgicos, juntamente com os metais zinco e chumbo vaporizam também os cloretos e fluoretos metálicos presentes. Nestes processos geralmente existe um excesso energético e por esta razão não há uma influência significativa da espécie mineral portadora do zinco (Zincita ou Franklinita), o que constitui uma vantagem considerável.

O óxido de zinco bruto que se forma na maioria dos processos pirometalúrgicos contém a maior parte do zinco, chumbo, haletos e pequenas quantidades de outros materiais arrastados do forno. Os cloretos de sódio e potássio existentes no PAE, que se volatilizam na temperatura do processo, impurificam o óxido bruto de zinco obtido. Segundo Nakayama [5], o excesso de cloretos no PAE tem dado causa a problemas na condensação do óxido de zinco em algumas instalações. Devido à temperatura de fusão relativamente baixa dos cloretos de sódio e potássio $\left(\sim 800^{\circ} \mathrm{C}\right)$, estas substâncias podem se liquefazer e aderir às paredes do equipamento durante a etapa de resfriamento, perturbando a condensação do $\mathrm{ZnO}$. Em razão disto, processos que operam em temperaturas mais elevadas, do tipo ESRF, e providos de sistemas especiais de resfriamento, conseguem minimizar o problema e obter um óxido bruto com maior teor de zinco.

Os cloretos e fluoretos que se acumulam no óxido bruto de zinco devem ser previamente retirados antes do processamento para a recuperação eletrolítica do zinco. Essa operação é realizada através de lixiviação alcalina, processo onde são removidos os sais solúveis, compostos principalmente de cloretos de sódio, potássio e sulfato de sódio [10]. Estes sais tanto podem ser recuperados na forma sólida quanto seguir com o efluente para tratamento adequado e descarte.

Considerando o processo Waelz, que é o mais utilizado em nível mundial, representando mais de $80 \%$ da capacidade instalada [11], resta como resíduo do processo a 'escória' ou 'clinquer de Waelz', que contém óxidos de ferro e cálcio originados do PAE e das adições. Este material necessita de destinação ambiental adequada.

Desta forma, em relação à composição do PAE, os processos pirometalúrgicos de reciclagem possuem as seguintes características:

a) Suportam uma larga variação na composição do PAE (matéria-prima), tanto em relação ao teor de zinco quanto na espécie mineral em que este metal se encontra.

b) Suportam a presença de cloretos, desde que não excessiva, sendo que alguns processos são mais sensíveis que outros neste aspecto. Estas espécies químicas volatilizam e se acumulam no óxido de zinco bruto coletado, de onde são removidas por lixiviação.

c) Geralmente demandam maiores investimentos, já que normalmente utilizam reatores sofisticados e operam em escala para obtenção de viabilidade econômica.

d) Apesar de representar a maior parte da capacidade instalada, o processo Waelz não recupera a totalidade do zinco do PAE, gera resíduos, e pode demandar frequentes paradas para manutenção em razão da maior ou menor tendência à

\footnotetext{
* Contribuição técnica ao $69^{\circ}$ Congresso Anual da ABM - Internacional e ao 14ํㅡㄹ ENEMET - Encontro Nacional de Estudantes de Engenharia Metalúrgica, de Materiais e de Minas, 21 a 25 de julho de 2014, São Paulo, SP, Brasil.
} 
formação de anéis gerados pela fusão incipiente da escória, a qual adere às paredes internas do forno tubular característico do processo.

e) Os processos pirometalúrgicos, considerando uma etapa única, não possuem viabilidade econômica para recuperar isoladamente alguns metais existentes no PAE, como o cobre e o níquel; no caso do processo Waelz, estes metais permanecem na escória.

f) Em processos onde há recuperação do ferro presente no PAE, o metal age como um 'coletor' para o cobre e níquel, o que pode inibir uma aplicação direta do produto (devido à matéria-prima diversa, o ferro-gusa não contém estes metais).

\subsection{A composição do PAE e os Processos Hidrometalúrgicos de Reciclagem}

Os processos hidrometalúrgicos de reciclagem do PAE têm como um dos principais motivadores a possibilidade de implementar a reciclagem das poeiras junto ou próximo aos pontos de geração [12]. Isto se dá em razão de que várias técnicas hidrometalúrgicas têm potencial para operar em menor escala, resultando em menores custos de transporte e investimento. A literatura apresenta um grande número de propostas que têm como princípio geral a atuação de compostos químicos específicos sobre o PAE em meio aquoso, por via ácida ou básica. Alternativamente, também existem processos fundamentados na dissolução da zincita $(\mathrm{ZnO})$ ou ainda utilização de solventes para separação de compostos de zinco de soluções previamente preparadas.

Em geral, o principal objetivo dos processos é obter uma solução rica em zinco com pureza suficiente para um processamento posterior; tanto para a obtenção do metal (HGl) quanto de um composto puro - tal como um óxido ou sulfato. Diferentemente dos processos pirometalúrgicos, dependendo da tecnologia empregada, existe a possibilidade de recuperação do cobre e de outros metais originalmente presentes no PAE (como cementos).

Apesar das diversas alternativas para as rotas hidrometalúrgicas, algumas dificuldades são comuns a todos estes processos. A principal delas refere-se à diversidade de composição do $\mathrm{PAE}$, tanto no aspecto químico quanto no mineral [13]. O maior conteúdo de zinco na espécie mineral zincita $(\mathrm{ZnO})$ favorece os processos hidrometalúrgicos em razão de que se trata de um composto de fácil dissolução tanto em meio ácido como básico, podendo também ser complexado por outras substâncias como sais de amônio.

Já a Franklinita $\left(\mathrm{Fe}_{2} \mathrm{ZnO}_{4}\right)$, é mais estável, requerendo condições mais enérgicas para a liberação do zinco. Neste contexto, sabe-se que poeiras com conteúdo elevado de zinco (>33\%) têm tendência a apresentar uma fração maior de zinco na fase zincita do que outras [7]. Portanto, no caso de implementação de processos hidrometalúrgicos, uma etapa prévia de aumento do teor de zinco no PAE deve ser considerada.

Este enriquecimento de zinco no PAE pode, por exemplo, ser efetuado pela recirculação das poeiras no forno elétrico a arco. Porém, caso as poeiras sejam processadas diretamente, muitas vezes é necessário uma etapa prévia pirometalúrgica para a decomposição da Franklinita; somente após se aplica a etapa hidrometalúrgica. É o que acontece, por exemplo, no processamento do PAE em meio básico proposto por Xia e Picles [13].

\footnotetext{
* Contribuição técnica ao 69ํ Congresso Anual da ABM - Internacional e ao 14ํㅡㄹ ENEMET - Encontro Nacional de Estudantes de Engenharia Metalúrgica, de Materiais e de Minas, 21 a 25 de julho de 2014, São Paulo, SP, Brasil.
} 


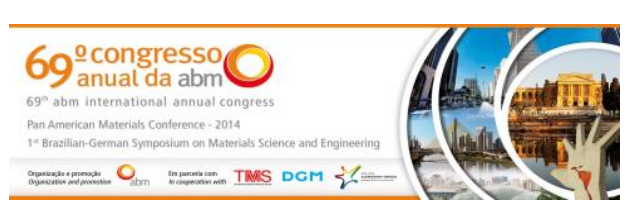

Em outras situações, como o ataque direto em meio sulfúrico, existe a necessidade do controle do $\mathrm{pH}$ e da temperatura para obtenção da seletividade da dissolução do zinco [14], evitando-se assim a dissolução de quantidades significativas de ferro.

Outra dificuldade crítica dos processos hidrometalúrgicos é o conteúdo de cloretos no PAE, os quais interferem nos processos de recuperação eletrolítica do zinco. Assim, processos que não são baseados em tecnologias com uso de compostos de cloro necessitam de uma etapa prévia de lixiviação para remoção destes cloretos solúveis.

Esta situação é encontrada na eletrólise de soluções de sulfato de zinco - que é a etapa final comum a vários processos tanto piro como hidrometalúrgicos. Neste processo são utilizados anodos de chumbo e cátodos de alumínio. Sinclair [9] informa que a presença do íon cloreto, em concentrações já na faixa de $400 \mathrm{mg} / \mathrm{L}$, provocam corrosão e geram gás cloro no anodo, prejudicando o ambiente laboral e impurificando as soluções de trabalho. Assim, baixas concentrações de cloretos nas soluções de sulfato de zinco são requeridas - na faixa de 50 a 100 mg/L [15].

Para contornar a questão da presença dos cloretos foram desenvolvidos processos à base de compostos de cloro, como o Ezinex, que se encontra em operação, e utiliza soluções de cloreto de amônio para dissolver a zincita. A solução de cátions, após purificação para remoção de chumbo, cobre e cádmio, é eletrolisada. Como as condições são mais severas, com geração de cloro no anodo, faz-se o anodo de grafita e o cátodo de titânio. Outra solução para o problema dos cloretos é a separação da solução de sulfato de zinco das impurezas (cloretos e metais tais como cobre e cádmio) através de solventes orgânicos específicos - como no processo Zincex [15]. Resta uma solução muito pura de sulfato de zinco para a eletrólise do metal.

Assim, considerando a composição e propriedades das poeiras de aciaria, e as possibilidades de processamento hidrometalúrgico, as seguintes particularidades devem ser consideradas:

a) As poeiras de aciaria possuem uma granulometria fina e têm, portanto, a tendência a reter grandes quantidades de líquido. Este fato prejudica os processos em si, devido à grande quantidade de água (ou soluções aquosas) a ser utilizada, tanto no processo como na lavagem. Isto causa perda de reagentes e produz grande volume de efluentes a serem tratados - além de requerer equipamentos de maiores dimensões para o processamento adequado das poeiras.

b) Os processos hidrometalúrgicos de reciclagem do PAE também geram um resíduo com alto conteúdo de umidade, dispendioso para condicionar, tanto para o retorno aos processos de fabricação de aço como para a destinação final em aterros.

c) Nos processos hidrometalúrgicos existe influência significativa da espécie mineral em que o zinco se encontra no PAE, sendo mais favorável a zincita.

d) A presença de cloretos no PAE prejudica de modo significativo a eletrodeposição do zinco. Para resolver este problema há necessidade de uma lixiviação prévia do PAE para redução destes compostos aos níveis de tolerância. Alternativamente, os processos podem ser à base de compostos de cloro, ou ainda as soluções de sulfato de zinco podem ser extraídas com auxílio de solventes, gerando soluções purificadas isentas de contaminantes.

e) Os processos hidrometalúrgicos têm a possibilidade de recuperar outros metais que comumente acompanham o PAE como, por exemplo, o cobre, níquel, prata, etc.

\footnotetext{
* Contribuição técnica ao $69^{\circ}$ Congresso Anual da ABM - Internacional e ao 14ํㅡㄹ ENEMET - Encontro Nacional de Estudantes de Engenharia Metalúrgica, de Materiais e de Minas, 21 a 25 de julho de 2014, São Paulo, SP, Brasil.
} 


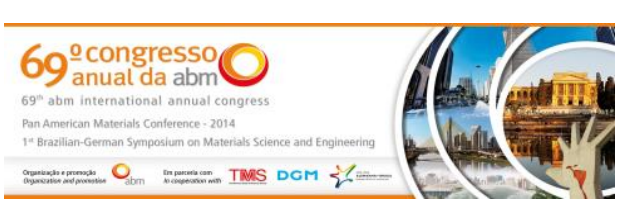

f) Estes processos, dependendo de seus objetivos, têm possibilidade de ser projetados para escalas menores de produção, podendo assim ser localizados próximos às usinas geradoras.

\section{RESULTADOS E DISCUSSÃO}

Várias elementos estão presentes na poeira da aciaria; alguns têm aumentado nos últimos anos, devido principalmente a alterações na qualidade e tipo das sucatas empregadas no processo de aciaria elétrica.

É especialmente importante acompanhar o comportamento do cloro, uma vez que os cloretos constituem uma impureza cada vez mais significativa, interferindo tanto nos processos piro quanto hidrometalúrgicos de reciclagem.

Uma abordagem considerando o efeito do cloro na reciclagem de uma poeira (com $17 \% \mathrm{Zn}$ ) por meio de um processo pirometalúrgico do tipo Waelz foi realizada com software FactSage, utilizando a composição básica (com adições de fundentes) mostrada na Tabela 1.

Tabela 1. Composição básica do PAE com adições

\begin{tabular}{lc}
\hline Constituinte & $\begin{array}{c}\text { Massa } \\
{[\mathrm{Kg}]}\end{array}$ \\
\hline $\mathrm{Fe} 2 \mathrm{O} 3$ & 30 \\
$\mathrm{ZnO} . \mathrm{Fe} 2 \mathrm{O} 3$ & 70 \\
$\mathrm{PbO}$ & 1 \\
$\mathrm{CaO}$ & 5 \\
$\mathrm{SiO} 2$ & 3 \\
\hline
\end{tabular}

Para fins de comparação, o efeito do cloro foi calculado adicionando-se à composição básica do PAE um quilograma de $\mathrm{NaCl}$ e um quilograma de $\mathrm{KCl}$.

O processo foi simulado na temperatura de $1100^{\circ} \mathrm{C}$, com uma quantidade mínima de coque, suficiente apenas para efetuar a redução dos óxidos de zinco (região redutora do processo). Os resultados estão apresentados nas Tabelas 2, 3 e 4.

Tabela 2. Composição da atmosfera (sem cloro e na presença de cloro) no forno Waelz, região redutora

\begin{tabular}{lrr}
\hline Gás [\% vol.] & Sem Cl & Com Cl \\
\hline $\mathrm{CO}$ & 51,9 & 49,7 \\
$\mathrm{Zn}$ & 29,6 & 29,1 \\
$\mathrm{CO}_{2}$ & 18,0 & 17,5 \\
$\mathrm{NaCl}$ & & 1,5 \\
$\mathrm{KCl}$ & & 1,3 \\
$\mathrm{~Pb}$ & 0,5 & 0,5 \\
Total & 100,0 & 99,6 \\
\hline
\end{tabular}

Observa-se, nas Tabelas 2 e 3, que o cloro passa totalmente à fase gasosa, mantendo a mesma proporção molecular já presente na carga sólida. Verifica-se também que parte do zinco permanece na escória.

\footnotetext{
* Contribuição técnica ao $69^{\circ}$ Congresso Anual da ABM - Internacional e ao 14ํㅡㄹ ENEMET - Encontro Nacional de Estudantes de Engenharia Metalúrgica, de Materiais e de Minas, 21 a 25 de julho de 2014, São Paulo, SP, Brasil.
} 


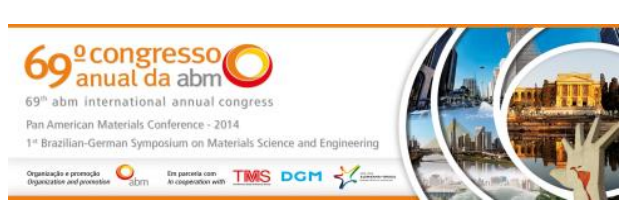

Tabela 3. Composição da escória de Waelz mostrando as fases condensadas (sem cloro e na presença de cloro), região redutora

\begin{tabular}{lrr}
\hline Massa [g] & $\mathrm{Sem} \mathrm{Cl}$ & Com Cl \\
\hline $\mathrm{FeO}$ & 68,4 & 68,7 \\
$2 \mathrm{CaO} . \mathrm{SiO} 2$ & 6,8 & 6,8 \\
$2 \mathrm{CaO} . Z n O .2 S i O 2$ & 1,7 & 1,7 \\
$\mathrm{ZnO}$ & 3,1 & 2,7 \\
$\mathrm{Fe}$ & 0,2 & 0 \\
\hline
\end{tabular}

É interessante verificar que, apesar dos cloretos de $\mathrm{Fe}$ e $\mathrm{Zn}$ possuírem alta pressão de vapor (Figura 1), apenas são observados $\mathrm{NaCl}$ e $\mathrm{KCl}$ gasosos. Isto pode ser explicado por meio de duas considerações: (i) a abundância relativa dos elementos $\mathrm{Na}, \mathrm{K} \mathrm{e} \mathrm{Cl}$ presentes na carga está na proporção correta para a formação destes compostos; (ii) o $\Delta \mathrm{G}^{\circ}$ de formação destes cloretos, na temperatura do processo, é muito menor do que a dos outros cloretos que poderiam se formar (de Fe e $\mathrm{Zn}$ ).

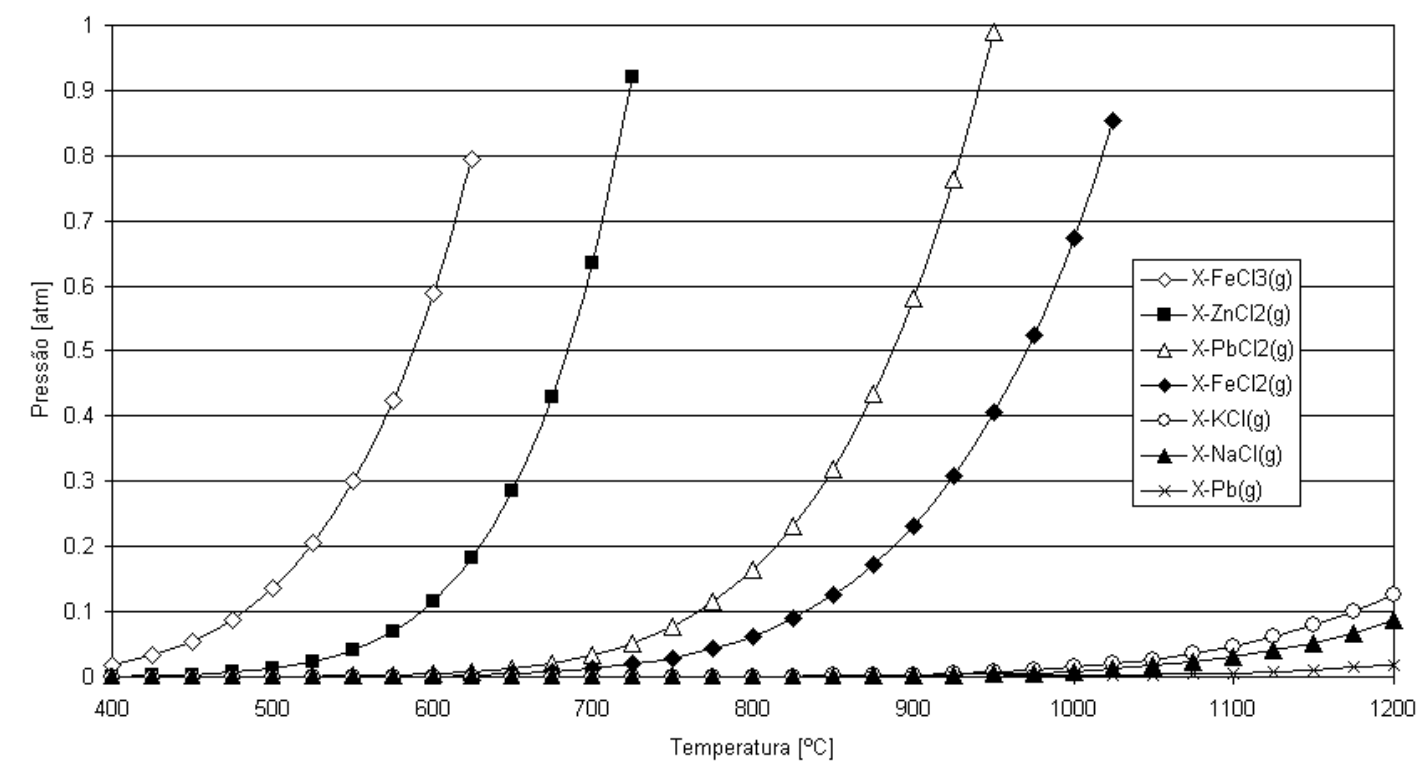

Figura 1. Pressões de vapor em função da temperatura para alguns cloretos selecionados e para o $\mathrm{Pb}$ (FactSage).

A distribuição do elemento $\mathrm{Zn}$ entre as fases gasosa e as fases condensadas foi determinada e pode ser observada na Tabela 4 . A presença do cloro promoveu um leve favorecimento da passagem do zinco para o gás.

Este resultado comprova que, de modo geral, os cloretos existentes originalmente no PAE são transferidos por volatilização e se acumulam no óxido de Waelz ( $\mathrm{nnO}$ impuro) que é obtido no processo.

Tabela 4.Distribuição do elemento $\mathrm{Zn}$ (sem cloro e na presença de cloro), porcentagem com base ponderal, na fase gasosa e nas fases condensadas

\begin{tabular}{lrr}
\hline Massa de Zn [g] & Sem Cl & Com Cl \\
\hline gás & 84,9 & 86,9 \\
sólida & 15,1 & 13,1 \\
\hline
\end{tabular}

\footnotetext{
* Contribuição técnica ao $69^{\circ}$ Congresso Anual da ABM - Internacional e ao 14ํㅡㄹ ENEMET - Encontro Nacional de Estudantes de Engenharia Metalúrgica, de Materiais e de Minas, 21 a 25 de julho de 2014, São Paulo, SP, Brasil.
} 


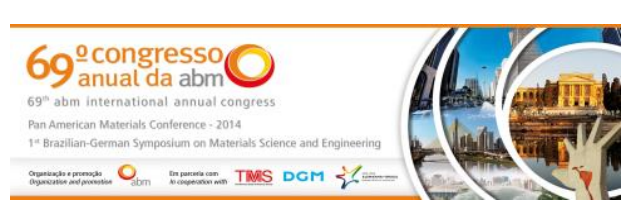

Já para os processos hidrometalúrgicos, a seletividade na dissolução do zinco pode ser vista um dos fatores decisivos de êxito - como, por exemplo, na dissolução das poeiras em meio sulfúrico. Com intuito de verificar teoricamente este comportamento, foi realizada uma simulação considerando a dissolução dos minerais zincita e franklinita em meio aquoso com ácido sulfúrico. Partiu-se de uma quantidade idêntica destes minerais e adicionou-se à solução quantidades crescentes de ácido sulfúrico, como pode ser observado na Tabela 5.

Tabela 5. Lixiviação de $\mathrm{ZnO}$ e de $\mathrm{ZnO} \mathrm{Fe}_{2} \mathrm{O}_{3}$ em ácido sulfúrico; massa das fases minerais condensadas [g] em função da quantia de ácido em um litro de água à $25{ }^{\circ} \mathrm{C}$ (note o aparecimento da fase hematita)

\begin{tabular}{cccc}
\hline $\mathrm{H}_{2} \mathrm{SO}_{4}[\mathrm{~g}]$ & $\mathrm{ZnO}[\mathrm{g}]$ & $\mathrm{ZnO}_{\mathrm{Fe}} \mathrm{O}_{3}[\mathrm{~g}]$ & $\mathrm{Fe}_{2} \mathrm{O}_{3}[\mathrm{~g}]$ \\
\hline 0 & 10,0 & 10,0 & \\
2 & 8,3 & 10,0 & \\
4 & 6,7 & 10,0 & \\
6 & 5,0 & 10,0 & \\
8 & 3,4 & 10,0 & \\
10 & 1,7 & 10,0 & \\
12 & 0,0 & 10,0 & 0,0 \\
14 & & 5,2 & 3,2 \\
16 & & 0,3 & 6,4 \\
18 & & 0,0 & 6,6 \\
20 & & & 6,6 \\
\hline
\end{tabular}

Pode ser observado que ocorre a dissolução preferencial da zincita. Resultados obtidos em ensaios de laboratório confirmam esta possibilidade mediante o controle do $\mathrm{pH}[14]$.

\section{CONCLUSÃO}

Com base na análise das informações da literatura e nas simulações efetuadas, pode-se concluir que o processamento das poeiras de aciaria para a recuperação do zinco é bastante complexo e existe uma influência significativa da composição do PAE. Os processos pirometalúrgicos são mais adaptáveis à variação da composição do PAE, porém têm um custo de implantação mais elevado e possuem limitações na qualidade do ferro recuperado quando são projetados também para esta função. Os processos hidrometalúrgicos são mais versáteis quanto à recuperação de outros metais como o cobre, porém são mais sensíveis a existência de zinco na espécie mineral Franklinita e outras impurezas como cloretos. Podem também gerar resíduos e efluentes com custo elevado de tratamento e disposição o que muitas vezes inviabiliza sua implementação.

\footnotetext{
* Contribuição técnica ao $69^{\circ}$ Congresso Anual da ABM - Internacional e ao 14ํㅡㄹ ENEMET - Encontro Nacional de Estudantes de Engenharia Metalúrgica, de Materiais e de Minas, 21 a 25 de julho de 2014, São Paulo, SP, Brasil.
} 


\section{REFERÊNCIAS}

1 Guézennec A-G, Huber J-C, Patisson F, Sessieq P, Birat J.-P, Ablitzer, D. Dust formation in electric arc furnace: birth of the particles. Powder Technology, 2005; 157: $2-11$.

2 Nyirenda RL. The Processing of Steelmaking Flue Dust: a Review. Minerals Engineering, 1991; 4, (7-11): 1003-1025.

3 Pickles CA. Thermodynamic Analysis of the Selective Chlorination of Electric Arc Furnace Dust. Journal of Hazardous Materials n 166, pp 1030-1042, 2008.

4 ABNT - Associação Brasileira de Normas Técnicas - Resíduos Sólidos Classificação NBR 10004:2004, 71 pg. Rio de Janeiro.

5 Nakayama M. New EAF Dust Treatment Process - ESRF, [acesso em 23 julho 2013]. Disponível em http://www.steelplantech.co.jp/wp-content/uploads/2012/08/201108_ EAF_Dust Treatment_fortlightMetalRecovery.pdf.

6 Bale CW, Chartrand P, Degterov SA, Erikson G, Hack K, Ben Mahfoud R, Melançon J,; Pelton AD, Petersen S. FactSage thermochemical software and databases. Calphad, Vol. 26, Nr.2, June, pp.189-228, 2002.

7 Buzin PJWK, Heck NC, Vilela ACF. EAFD - A thermodynamic analysis and classification of dust types. Proceed,. $45^{\text {th }}$ Steelmaking Seminar - International, 2014, Porto Alegre, Rio Grande do Sul.

8 Southwick LM. Still no simple solution to processing EAF dust. Steel Times International, march, 2010, pp 43-45 [acesso em 15 julho 2013]. Disponível em www.steeltimesinter.com.

9 Sinclair RJ. The Extractive Metallurgy of Zinc. The Australasian Institute of Mining and Metallurgy, Spectrum series, volume 13, 2005.

10 Penchel Jr AS, Takayama Filho T, Dias MJ, Mello LS. Agregação de valor ao sal misto. XXV Encontro Nacional de Tratamento de Minérios e Metalurgia Extrativa \& VIII Meeting of the Southern Hemisphere on Mineral Technology, Goiânia-Go, 20 a 24 de outubro de 2013.

11 Rutten J. Application of the Waelz Technology on Resource Recycling of Steel Mill Dust. Encol/SEASI Bangkok-Thailand, 2006, [acesso 20 março 2013]. Disponível em http://www.valo.res.com/pdf/ Leoben2006-EN.pdf.

12 Nakamura T, Shibata E, Takasu T, Itou H. Basic consideration on EAF dust treatment using hydrometallurgical processes. Resources Processing $n^{\circ}$ 55, $p$ 144-148, 2008.

13 Xia DK, Pickles CA. Caustic roasting and leaching of electric arc furnace dust. Canadian Metallurgical Quartely, vol 38, n³, pp175-186, 1999.

14 Havlik T, Souza BV, Bernardes AM, Schneider IAH, Miskufova, A. Hydrometallurgical processing of carbon steel EAF dust. Journal of Hazardous Materials, B135, pp 311-318, 2006.

15 Frias C. Secondary Zinc. International Mining, October 2009, pp 28-29, [acesso em 18 janeiro 2014]. Disponível em http://www.Infomine.com/library/publications/docs/ InternationalMining/Frias2009.pdf.

\footnotetext{
* Contribuição técnica ao 69ํ Congresso Anual da ABM - Internacional e ao 14ํㅡㄹ ENEMET - Encontro Nacional de Estudantes de Engenharia Metalúrgica, de Materiais e de Minas, 21 a 25 de julho de 2014, São Paulo, SP, Brasil.
} 